\title{
How Theological Librarians Can Help Change the World
}

\author{
Addressing Knowledge and Gender Gaps in \\ the World's Largest Encyclopedia
}

Kerrie Burn, Mannix Library, Catholic Theological College, University of Divinity

\begin{abstract}
The 1000 Women in Religion Project is working towards adding 1,000 biographies about women to Wikipedia, where only $18 \%$ of entries are about women. Knowledge and gender gaps on Wikipedia are well documented and exist despite the platform's idealistic early goal of providing "free access to the sum of all human knowledge." This paper details the Australian Women in Religion Project, a collaborative initiative under the auspices of the University of Divinity. The experience of the Australian project can be used as a model for similar projects in other parts of the world. Understanding Wikipedia's policies around notability, reliability, secondary sources, and conflict of interest is important. There are many benefits to participating in Wikipedia projects like this and theological librarians are well placed to contribute. This is a practical way to highlight noteworthy women in religion while addressing issues of systemic knowledge and gender bias on platforms like Wikipedia.
\end{abstract}

\section{BACKGROUND}

My presentation will share a little about the Australian Women in Religion Wikipedia Project, what it is, its connection to a wider international project, and how you as a theological librarian may be able to get involved. Hopefully you will be inspired to contribute to the project and help change the world, one Wikipedia edit at a time.

\section{WOMEN IN RELIGION PROJECT}

The 1000 Women in Religion Project is a major initiative of the Women's Caucus of the American Academy of Religion (AAR) and 
the Society of Biblical Literature (SBL). It is supported by Atla and the Parliament of the World's Religions. I first heard about the project when I attended the 2019 Atla conference in Vancouver and had a chance conversation over morning tea with the chair of the project, Colleen Hartung. Colleen had a poster presentation and also hosted a Wiki edit-a-thon at the conference. She was very enthusiastic when I suggested that the University of Divinity might coordinate an Australian contribution to the project.

\section{AIMS OF THE PROJECT}

The 1000 Women in Religion Project is working to raise up the underrecognized work of women in the world's religious and wisdom traditions by adding at least 1,000 biographies to Wikipedia. This is a really practical way to lift up the work of women in religion in ways that help address the current gender imbalance on Wikipedia and help reform the gender biases that shape our systems of knowledge production.

"The more we can document and highlight the contributions of women leaders in their religious and spiritual traditions, the more we can change the perception that women have not been leaders."

This is a quote by Elizabeth Ursic. Amongst other roles she is the co-chair of the Women's Caucus of the AAR/SBL. We've all heard the adage that history is written by the winners. When we think about the stories that are familiar to us, I think it pays to consider:

- Who writes the stories?

- Who benefits from the stories?

- Who is missing from the stories?

The 1000 Women in Religion Project is one practical way of highlighting the contributions of some of the women whose stories have not been adequately recorded and communicated.

\section{WIKIPEDIA}

Women on Wikipedia - Knowledge and Gender Gaps

The extent of the under-representation of women is clear from the data. Wikipedia's own research shows that only about $18 \%$ of biographies on Wikipedia are about women. And why is this? There are lots of reasons, but mainly because there are so few female editors. 
Some estimates indicate that less than $10 \%$ of editors across Wikipedia projects are women. This means that in a whole range of fields, notable women and their achievements are missing from Wikipedia.

Obviously women don't have to just edit women's content. We need women to be editing ANY content, because bias is evident at lots of levels - what's covered, the length of articles and the kinds of language used.

The gender gap on Wikipedia is well documented. The 1000 Women in Religion Project is just a beginning. Many hurdles and difficulties remain:

- Most biographies are about men. In fact, as a result of notability and sourcing issues almost all Wikipedia's pre-twentiethcentury biographies are about men.

- Most articles are written by men.

- Most of the content policy is written by men, including Wikipedia's notability and sourcing standards.

- These notability and sourcing policies determine which articles about women are accepted on Wikipedia.

This gender bias has consequences. For example, Donna Strickland didn't have a Wikipedia page until October 2, 2018, when she won the Nobel Prize in Physics. One can only presume that she was doing notable work prior to receiving this award.

\section{Why Does Wikipedia Matter?}

Wikipedia is arguably the greatest crowd-sourced project in the world. Everything you read on the platform is created by a community of approximately 97,000 registered users-editors who voluntarily contribute and who work in accordance with editing guidelines and principles decided on by the community. Wikipedia is the largest and most-read reference work in history and one of the most-visited websites in the world. It has over 56 million articles in over 320 languages and attracts 1.7 billion unique visitors monthly. Despite librarians and others not thinking too highly of Wikipedia as a reference source in days gone by, we all know that it is often the first stop for any sort of basic research.

Wikipedia aims to be, and is fast becoming, part of the fundamental infrastructure of machine learning, knowledge services, and linked data. So every time you do a Google search and informa- 
tion appears in the knowledge panel on the right hand side of your search results, more often than not this information is coming from Wikipedia.

\section{Wikipedia's Mission}

So this is Wikipedia's goal: "Imagine a world in which every single human being can freely share in the sum of all knowledge.” That sounds like something that most theological librarians could say Amen to! Unfortunately, despite the platform's idealistic early goal of providing "free access to the sum of all human knowledge," knowledge and gender gaps on Wikipedia are well documented.

The system of free, open content that is part of Wikipedia's original vision of democratising knowledge also presents a risk. And that risk is that Wikipedia reproduces and amplifies the inequities already present in the world, including gender inequity.

However, gender gaps are just the tip of the iceberg. Like the rest of society there are a range of systemic biases that result in various equity and inclusion issues for Wikipedia. Gender, race, national, regional, language, content, and other biases result in some voices being under-represented.

It is difficult to claim that Wikipedia is an encyclopedia of the sum of all knowledge, when only some knowledge meets Wikipedia's criteria for inclusion. Much of these criteria are based on Western concepts of scientific method and scholarly communication practices. But what about Indigenous cultures that may have different ways of preserving and sharing knowledge, perhaps based on a more oral tradition, that can't be cited in a book or journal article? What about when knowledge is shared through stories, embodied in dance or cultural performance?

Systemic bias issues will not fix themselves, which is why projects such as the 1000 Women in Religion Project have arisen and why they are so valuable. We can help to address biases one Wikipedia edit at a time.

\section{Five Pillars of Wikipedia - "the Rules"}

Let's talk a bit more about Wikipedia. Founded in 2001 (celebrating its twentieth birthday in 2021), Wikipedia is not without rules. These fundamental principles, known as the five pillars, are decided upon and monitored by the community of editors. This community has 
defined the most important things to consider when we edit Wikipedia. I'll briefly unpack a few of these.

1) Wikipedia is an encyclopedia.

This means that articles should be written in a straightforward, plain language style and sources cited to back up any factual claims. Wikipedia editing is not meant to be a creative writing exercise. No original research is involved, so it is not a place for new analysis or ideas. Editors must attribute viewpoints to the people who hold them and avoid stating conclusions except when attributed to a specific source.

2) Wikipedia is written from a neutral point of view. All articles should be written from a neutral point of view. Editors should not take sides or promote one particular point of view over another. They should avoid expressing opinions, and use non-judgmental language. The aim is to achieve balance across a range of views, describing all significant points of view without bias and using reliable sources.

Conflict of interest is also something to be avoided. You should not create or edit Wikipedia articles that are in your own interests, nor in the interests of your external relationships, such as your employer or close colleagues.

3) Wikipedia is free content that anyone can use, edit, and distribute.

Wikipedia is all about openness. All content in Wikipedia is released under a Creative Commons license which means that as long as you attribute it, all material from Wikipedia can be used by anyone, for any purpose, including commercial purposes.

Wikipedia is very strict on removing copyright-protected material that does not meet the requirements of this licence. At the same time plagiarism is not allowed, so if the content has been cut and pasted, and not paraphrased or rewritten, it will be removed. 
4) Wikipedia's editors should treat each other with respect and civility.

This includes not engaging in personal attacks or edit wars, acting in good faith and assuming the same of others, being welcoming to newcomers, and discussing conflicts calmly when they do arise, with a view to dispute resolution.

5) Wikipedia has no firm rules.

Policies and guidelines exist but are open to interpretation and evolution over time.

\section{Notability}

This is one of the hardest issues to deal with when addressing the gender gap on Wikipedia. Who is notable enough to be on Wikipedia? The definition says that:

"A person is presumed to be notable if he or she has received significant coverage in reliable secondary sources that are independent of the subject."

Unfortunately this is not a simple matter, particularly when it comes to under-represented groups, such as women or Indigenous people, who sometimes don't have as many references to draw upon. The bias runs deep and it can be very challenging.

When attempting to create articles for under-represented people, it is important to focus on any markers of notability that are able to be verified in reliable secondary sources. Personal websites and blogs written by the subject do not count as independent sources and are not valued indicators of a subject's notability.

Some suitable markers of notability include: academic degrees; awards from respected organizations; positions on boards or other leadership roles within traditionally recognized institutions; having a body of work, publications, or other moments of significance; credited for initiating, establishing, or creating significant institutions or organizations; being significant or influential in a public versus the domestic sphere.

\section{Reliable Sources}

This is another area where librarians have some expertise. All information on Wikipedia needs to be verifiable, and all facts presented need to be referenced by citing reliable sources. Wikipedia editors 
aim to use the best sources they possibly can. This includes third party sources with a reputation for fact-checking, such as books published by academic presses, peer-reviewed academic journals, international newspapers, online archives, and internet sources with .org or .edu. In contrast, personal websites and Facebook pages are not highly regarded as sources of independent information.

Studies show that there is less biographical coverage of women in books, encyclopedias, journals, news media, and more. This deficit of reliable secondary sources is one of the factors that frustrates our editors and makes it difficult to write a successful submission for some women on the 1000 Women in Religion list.

The Women's Caucus of the American Academy of Religion (AAR) and the Society of Biblical Literature (SBL) are engaged in some practical efforts to address this problem. One initiative is hosting a panel at the annual meeting of the AAR and the SBL on women's biographies. Another is working on a yearly monograph volume being published by Atla in its Women in Religion series, which contains biographies about women not on Wikipedia. This publication can then be used as a secondary source to support the writing of new Wikipedia articles.

\section{AUSTRALIAN WOMEN IN RELIGION PROJECT}

The Australian Project is part of the larger international 1000 Women in Religion Project. After meeting Colleen Hartung, the Chair of the 1000 Women in Religion Wikipedia Project at the 2019 Atla conference in Vancouver, I initiated an Australian contribution to the project under the auspices of the University of Divinity, where I am employed as a Library Manager at Mannix Library.

Initially a small working group was established. The group included academic staff from several colleges associated with the University, historians, biblical scholars, a PhD student, and myself, and we also had the enthusiastic support of the Vice Chancellor. The University's Strategic Plan had a Gender \& Theology Goal, and a target to "Contribute 100 entries for Australian women in religion to the 1000+ Women in Religion Project” in 2020 was added to this goal. 


\section{PROGRESS TO DATE}

1) Monthly International Project meetings - committee and editing meetings - this ensures that the Australian project maintains its links with the overarching 1000 Women in Religion Project.

2) University of Divinity Working Group - the membership of this group has evolved over time.

3) Created using LibGuides - https://divinity.libguides.com/feminist/women-in-religion.

4) Created Resources:

a) List of Australian (and some New Zealander) women there are now almost 500 women on the list.

b) Collated biographical data about each woman into a huge Excel spreadsheet.

c) Uploaded this data to Wikidata using QuickStatements tool.

d) Compiled list of Australian Women in Religion Sources reliable secondary sources that could be used by editors.

e) Created Wikipedia Article Guide.

This provided a guide for writing biographies using a standard template in Word, for those interested in the project but who didn't necessarily want to become Wikipedians. More experienced editors could then use these documents to create new articles. We tried to overcome barriers to participation by having a range of tasks that people could assist with.

5) Promotion: We used a variety of social media tools and wrote online news articles. As a result, many new names were suggested, and the list of Australian women continued to grow.

6) Engagement with Wikimedia Australia: I began working with Wikimedia Australia, and the association has provided expertise, promoted our project and events, and provided expert Wikipedians to facilitate our edit-a-thons and work with our core group. 
7) The core group of four members continued to meet regularly with others connecting to the project by suggesting new names and participating in edit-a-thons.

8) Research assistant employed. This was made possible after a successful grant application.

9) Wikipedia Visiting Scholar appointed at the University of Divinity. This arrangement came about when a member of the 1000 Women in Religion group volunteered to be a visiting Wikipedia Scholar to work with us on the Australian project. The appointee, who is an experienced Wikipedian based in the United States, has made a valuable contribution to our project and is a member of our core group. Becoming a University Scholar provides her with access to the University's online resources. The University of Divinity is also acting as a pilot group for Wikimedia Australia, which is using us to establish a local Wikipedia Visiting Scholar program.

10) Held an in-person edit-a-thon in March 2021: Unfortunately, like lots of events in 2020 our first planned edit-a-thon had to be cancelled.

11) Hosted a Zoom edit-a-thon in June 2021.

At edit-a-thons new editors create Wikipedia user accounts, add content to their user page, and learn some of the basics of editing Wikipedia, formatting, citing references, etc. Participants take on to edit stub articles, or more experienced editors will create new articles for women on our list. Beforehand we will have created a list of Articles to Create and Articles for Improvement. New editors work alongside more experienced editors, and everyone learns from each other. At the end of the sessions, new editors often have a more experienced editor review their article and move it from a draft article in someone's sandbox, to a live article.

12) Project has now created over 65 new Wikipedia articles, so we are well on our way to reaching our target of 100 new articles in 2021. It is likely that not all the women on our list will satisfy Wikipedia's notability requirements. Part of the project has been to identify the low hanging fruit, to create these articles first, and to learn from the process. 
13)Applied for a research grant to progress the project. The Australian Women in Religion Project has expanded beyond being just a Wikipedia project. We are now engaged with researchers at several other Universities in Australia. Members of the core group are also contributing to several publications related to the international Women in Religion project. Locally we are also planning a digitization project to make some early publications of Australian feminist theology groups and women's religious collectives available online.

The Excel template developed by the Australian project can now be used as a model for similar projects in other parts of the world. The spreadsheet I created included a large number of fields. Some related to biographical information such as family and given names, date of birth, date of death, occupation, educational affiliations, religion, and religious order. I also included as many identifiers as I could. These included VIAF ID, Australian Dictionary of Biography ID, National Library of Australia Trove ID, Australian Women's Register ID, Library of Congress Authority ID, ISNI, and ORCID IDs. These identifiers connect to other datasets, and in themselves can be an indicator of notability.

One of the pieces of information that can be added in Wikidata indicates that the person is part of the 1000 Women in Religion Wikimedia Project. When this field is included on each person's Wikidata page they automatically get added to the auto-generated 1000 Women in Religion list on Wikipedia.

https://en.wikipedia.org/wiki/Wikipedia\%3AWikiProject_1000_ Women_in_Religion\%2FList_of_English_Wikipedia_Articles

This list now includes over 1,200 women. Those highlighted in red have data about them in Wikidata, but they don't yet have a Wikipedia page. As each woman has a Wikipedia article created the link changes from red to blue.

Some of the Wikipedia articles that already exist are very brief known as "Stub" articles - and part of the project is also to expand these and develop them into more substantial articles. 


\section{SOURCES}

Australia is fortunate to have some great sources that we have been able to use to compile the list of women and find additional references to reliable secondary sources. Inclusion in some of these sources becomes an additional unique identifier, and is itself an indicator of notability. To assist editors to create Wikipedia articles I also created a display of print items from our Mannix Library collection and a Course Reserves list of books that could be used as source material. Some of the most significant resources include:

- The Australian Dictionary of Biography - http://adb.anu.edu.au/

- The Australian Women's Register - http://www.womenaustralia. info/leaders/index.html

- The Encyclopedia of Women \& Leadership in Twentieth-Century Australia - https://www.womenaustralia.info/leaders/

- Trove - https://trove.nla.gov.au/

\section{PROJECT WEBSITE - WIKIPEDIA ARTICLES - PROJECT DASHBOARD}

As new articles are created, they are added to a tab on our main LibGuides homepage - https://divinity.libguides.com/feminist/wikipedia

A Dashboard page also collates data related to the Australian Women in Religion Project and keeps this information in one place - https://outreachdashboard.wmflabs.org/courses/University_of_ Divinity/Australian_Women_in_Religion_Wikipedia_Project_(20202025)/home

\section{FUTURE DIRECTIONS - NEXT STEPS?}

- Create more new and improved existing Wikipedia articles.

- More edit-a-thons. We have also recently initiated a weekly Wiki-Wednesday session. Individuals can join a Zoom meeting, and either continue working on articles, and/or seek assistance with any editing issues. This is a great way to learn together and to collaborate on projects of mutual interest.

- Continue to promote the project to a wider audience. 
- Spin-off projects:

- Digitization of Australian feminist theological journals and other publications such as newsletters from Australian women's religious collectives, and making these available online.

- Publications - including contributions to Atla's Women in Religion series, and potentially a volume devoted to Australian women in religion.

- Some of this work will be facilitated if several recent grant applications are successful.

\section{ROLE OF LIBRARIANS}

There are many ways that theological librarians can add value to initiatives like the 1000 Women in Religion Project. As well as having subject expertise related to the world's religious and spiritual traditions, librarians also have relevant technical expertise and understand the importance of accurate metadata, unique identifiers, and other international standards. Librarians tend to be organized, value open access to knowledge, are used to working collaboratively and navigating in an online environment, have access to databases and other resources, and can identify and accurately cite reliable secondary sources.

Because theological librarians have the skills required to access information, conduct independent research, and develop new content, they can make great Wikipedia editors and are encouraged to consider contributing to the project.

These are also a variety of ways for individuals to contribute:

1) Join the Project

https://en.wikipedia.org/wiki/Wikipedia:WikiProject_1000_

Women_in_Religion

2) Become a Wikipedia editor - Write about women you are interested in

3) Suggest new names for the list

4) Start your own regional group

5) Identify gaps (and fill them)!

6) Contribute to other projects, e.g. Women in Red

Whatever your area of interest, I would encourage you to be involved. 


\section{CONCLUSION}

Contributing to this project has many worthwhile benefits. Becoming a Wikipedia editor provides an opportunity to build new skills. The 1000 Women in Religion Project is an effort to raise up noteworthy women in religion. It is a practical way of addressing knowledge and gender gaps on Wikipedia. It makes information about women in religion visible and freely available and helps to address knowledge equity issues and other forms of systemic bias on the platform.

The project is an opportunity to contribute to one of the world's largest-ever crowd-sourced projects. It also promotes libraries and librarians as important contributors to open knowledge creation and dissemination. I encourage all theological librarians to jump on board, and together, let's help change the world!

\section{BIBLIOGRAPHY}

Adams, Julie. 2014. "Statement on Adams/Brückner Wikipedia Research Project (November 2014).” Accessed August 11, 2021. https://sociology.yale.edu/publications/statement-adamsbrckner-wikipedia-research-project-november-2014.

Wikipedia. n.d. "Gender bias on Wikipedia." Accessed August 11, 2021. https://en.wikipedia.org/wiki/Gender_bias_on_Wikipedia.

.n.d. "Wikipedia:About.” Accessed August 11, 2021. https:// en.wikipedia.org/wiki/Wikipedia:About.

. n.d. "Wikipedia:Notability.” Accessed August 11, 2021. https:// en.wikipedia.org/wiki/Wikipedia:Notability.

n.d. "Wikipedia:Notability (people).” Accessed August

11, 2021. https://en.wikipedia.org/wiki/Wikipedia:Notability_ (people).

_ n.d. "Wikipedia:Verifiability.” Accessed August 11, 2021. https://en.wikipedia.org/wiki/Wikipedia:Verifiability.

- n.d. "Wikipedia:WikiProject Women in Red.” Accessed August 11, 2021. https://en.wikipedia.org/wiki/Wikipedia:WikiProject_ Women_in_Red. 


\section{PROJECT-RELATED WEBSITES}

https://en.wikipedia.org/wiki/Wikipedia:WikiProject_1000_Women_ in_Religion

https://divinity.libguides.com/feminist/women-in-religion

https://divinity.libguides.com/feminist/wikipedia

https://outreachdashboard.wmflabs.org/courses/University_of_ Divinity/Australian_Women_in_Religion_Wikipedia_Project_ (2020-2025)/home

https://en.wikipedia.org/wiki/Wikipedia\%3AWikiProject_1000_ Women_in_Religion\%2FList_of_English_Wikipedia_Articles https://www.womenscaucusaarsbl.org/1000-women-in-religionproject

The Australian Dictionary of Biography - http://adb.anu.edu.au/

The Australian Women's Register - http://www.womenaustralia.info/ leaders/index.html

The Encyclopedia of Women \& Leadership in Twentieth-Century

Australia - https://www.womenaustralia.info/leaders/

Trove - https://trove.nla.gov.au/ 